\title{
Perbandingan Kejadian Kecemasan antara Sif Kerja Malam dan Sif Kerja Pagi pada Satuan Pengamanan Universitas Islam Bandung
}

\author{
Muhammad Faishal Kartadinata, ${ }^{1}$ Nugraha Sutadipura, ${ }^{2}$ Raden Ganang Ibnu Santosa, ${ }^{3}$ \\ Eka Nurhayati, ${ }^{3}$ R.Kince Sakinah ${ }^{3}$ \\ ${ }^{1}$ Program Studi Pendidikan Dokter, ${ }^{2}$ Bagian Biomolekuler, \\ ${ }^{3}$ Bagian Ilmu Kesehatan Masyarakat, Fakultas Kedokteran, Universitas Islam Bandung
}

\begin{abstract}
Abstrak
Kementerian Kesehatan Republik Indonesia mengkategorikan kecemasan sebagai salah satu gangguan mental emosional. Riset Kesehatan Dasar tahun 2013 mengungkapkan prevalensi penduduk yang mengalami gangguan mental emosional secara nasional adalah 6,0\%. Faktor risiko yang dapat memengaruhi kecemasan pada seseorang di antaranya beban kerja, yaitu sif kerja terutama sif kerja malam. Tujuan penelitian ini adalah melihat proporsi kejadian kecemasan antara sif kerja pagi dan sif kerja malam pada satuan pengamanan. Metode penelitian ini adalah kuantitatif observasional melalui pendekatan cross-sectional. Sampel penelitian ini adalah satuan pengamanan di Universitas Islam Bandung. Dalam periode Maret-April 2018 jumlah sampel yang berhasil didapatkan 23 orang dengan pengukuran sebanyak 2 kali, yaitu ketika menyelesaikan sif pagi dan ketika menyelesaikan sif malam. Pengukuran kejadian cemas menggunakan lembar kuesioner Depression Anxiety Stress Scale 42 (DASS 42). Hasil penelitian menunjukkan bahwa sif pagi memiliki persentase kejadian cemas 15 dari 23 orang dan sif malam 14 dari 23 orang. Hasil Uji statistik McNemar's Chi-Square tidak terdapat perbedaan proporsi kecemasan antara sif kerja pagi dan sif kerja malam ( $\mathrm{p}=0,76 ; \mathrm{PR}=0,93$; IK 95\%: 0.59-1,45). Simpulan penelitian ini tidak terdapat perbedaan proporsi kecemasan antara sif kerja pagi dan sif kerja malam.
\end{abstract}

Kata kunci: DASS 42, gangguan mental emosional, kecemasan, satuan pengamanan, sif kerja malam

\section{Comparison of Anxiety Events between Night Shift and Morning Shift on Security in Bandung Islamic University}

\begin{abstract}
The Ministry of Health of the Republic of Indonesia categorizes anxiety as one of the mental disorders. Basic Health Research in 2013 reveals the prevalence of people with mental disorders nationally at 6.0\%. Risk factors that can affect anxiety in a person such as workload is shift work, especially night shift work. The purpose of this study was to assess the proportion of anxiety occurrence between morning shift and night shift on security unit. This research method was quantitative observational through cross-sectional approach. The sample in this study was a security unit at the Bandung Islamic University. The research was doing between March-April 2018. The number of samples obtained were 23 people with measurements as much as 2 times, record one after finishing the morning shift and one after finishing the night shift. Measurement of anxiety events using Depression Anxiety Stress Scale 42 (DASS 42) questionnaire. The results showed that morning shift had an anxious incidence percentage 15 of 23 samples and the night shift 14 of 23 samples. The statistical results of McNemar's Chi-Square showed no difference in the proportion of anxiety between morning shift and night shift ( $\mathrm{p}=0.76, \mathrm{PR}=0.93,95 \% \mathrm{CI} 0.59-1.45)$. The conclusion of the study there is no difference in the proportion of anxiety occurrence between morning shift and night shift.
\end{abstract}

Key words: Anxiety, DASS 42, mental disorder, night shift work, security worker 


\section{Pendahuluan}

Gangguan mental emosional merupakan kondisi medis yang mengganggu kemampuan berpikir, merasakan, mood, berhubungan dengan orang lain, dan fungsi sehari-hari. Masalah tentang kesehatan ini dapat secara bermakna memengaruhi seseorang untuk berpikir, bertingkah laku, dan juga berinteraksi dengan orang lain. Diagnosis gangguan mental dapat ditegakkan melalui kriteria yang sudah terstandardisasi. Contoh keadaan kelainan mental yang serius antara lain depresi mayor, skizofrenia, gangguan bipolar, kelainan obsesif kompulsif, dan juga gangguan kecemasan. ${ }^{1,2}$ Riset Kesehatan Dasar mengkategorikan gangguan kecemasan itu termasuk sebagai gangguan mental emosional. ${ }^{3}$

Riset Kesehatan Dasar (Riskesdas) pada tahun 2013 telah mengungkapkan bahwa prevalensi penduduk yang mengalami gangguan mental emosional secara nasional adalah 6,0\% (37.728 orang dari subjek yang dianalisis). Penelitian didapatkan melalui self reporting questionnaire (SRQ) yang terdiri atas 20 butir pertanyaan yang ditunjukkan kepada anggota rumah tangga berusia 15 tahun atau lebih. Provinsi Jawa Barat memiliki prevalensi gangguan mental emosional sebesar 9,3\%. ${ }^{3}$

Beban kerja adalah kemampuan tubuh pekerja dalam menerima pekerjaan. Beban kerja pekerjaan memiliki dua sumber, yaitu dari luar dan dari dalam. Sumber yang berasal dari luar contohnya adalah sif kerja, sedangkan yang berasal dari dalam contohnya adalah kondisi kesehatan pekerja. ${ }^{4}$

Kegiatan yang membutuhkan tindakan operasi atau pelayanan selama 24 jam biasanya menggunakan metode sif kerja. Pekerjaan dilakukan secara bergiliran untuk dapat memenuhi waktu bekerja selama 24 jam. Sif kerja diterapkan untuk memanfaatkan sumber daya yang sudah ada, meningkatkan produksi kerja, maupun memperpanjang durasi pelayanan. Pembagian waktu sif kerja dapat terbagi menjadi 3 waktu (pagi, sore, dan malam) atau 2 waktu (pagi dan malam). ${ }^{5}$

Sif malam diasosiasikan dengan bermacam-macam keluhan mental termasuk kecemasan. ${ }^{6}$ Penelitian Yani dkk. ${ }^{7}$ menunjukkan bahwa terdapat hubungan antara sif kerja malam dan kejadian kecemasan.

Satuan pengamanan (satpam) merupakan tenaga kerja yang berperan dalam melayani kebutuhan sosial atau organisasi dalam bidang keamanan. Tugas seorang satpam adalah menjaga keamanan suatu lingkungan. Dalam menjalankan tugas menjaga keamanan selama 24 jam, satpam juga menerapkan sistem sif kerja. ${ }^{8}$

Universitas Islam Bandung (Unisba) mempunyai satpam dengan sif kerja pagi dan sif malam yang dilakukan secara bergiliran dengan urutan dua hari sif malam, kemudian 2 hari sif pagi, atau kebalikannya. Setelah melakukan sif kerja pagi-malam atau malampagi maka satpam diberikan dua hari istirahat. Setiap sif kerja memiliki jam kerja selama dua belas jam yang merupakan di luar jam kerja normal. Melihat sif kerja yang diterapkan pada satpam di Universitas Islam Bandung, penulis tertarik mengetahui perbandingan kejadian kecemasan antara sif kerja malam dan sif kerja pagi pada satpam di Universitas Islam Bandung.

\section{Metode}

Penelitian adalah penelitian kuantitatif observasional memakai rancangan studi cross-sectional. Subjek penelitian adalah satuan pengamanan di Universitas Islam Bandung selama periode Maret sampai April 2018. Sampel penelitian yang didapatkan adalah 23 orang melalui simple random sampling dan dilakukan 2 (dua) kali pengukuran, yaitu saat menyelesaikan sif pagi dan pada saat menyelesaikan sif malam. Kriteria eksklusi penelitian adalah tidak hadir saat penelitian, mengalami rotasi kerja, sedang masa terapi kejiwaan, atau pernah mengalami gangguan kejiwaan. Kriteria inklusi penelitian adalah anggota satuan pengamanan yang menyelesaikan sif kerja malam dan sif kerja pagi selama dua hari serta mengisi kuesioner secara lengkap.

Responden yang telah memenuhi kriteria penelitian lalu diberikan penjelasan mengenai penatalaksanaan penelitian ini dan menandatangani persetujuannya (informed consent). Semua responden mengisi lembar kuesioner Depression Anxiety Stress Scale 42 (DASS 42) dengan panduan oleh peneliti pada saat pengisian. Data hasil pengukuran itu selanjutnya dilaksanakan uji analisis mempergunakan software statistik. Uji yang dilakukan adalah analisis univariat dan analisis bivariat. Uji analisis bivariat yang digunakan adalah Uji McNemar's Chi-Square.

Penelitian ini sudah mendapatkan persetujuan etik (ethical approval) Nomor 333/Komite Etik FK/ III/2018 dari Komite Etik Penelitian Kesehatan Fakultas Kedokteran Unisba.

\section{Hasil}

Hasil penelitian distribusi data frekuensi kejadian kecemasan pada sif pagi dan sif malam terdapat pada Tabel 1 serta perbandingan kejadian kecemasan antara sif kerja pagi dan sif kerja malam disajikan pada Tabel 2. Seluruh responden penelitian laki-laki usia produktif menurut Kementerian Kesehatan Republik Indonesia, yaitu usia 15-64 tahun. ${ }^{9}$ Usia terendah 19 tahun dan tertinggi 42 tahun dengan rerata usia 28 tahun. Lama kerja subjek penelitian selama $\geq 5$ tahun berjumlah 11 dari 23 orang, sedangkan $<5$ tahun terdapat 12 dari 23 orang. Pengelompokan lama kerja dibagi berdasar atas penelitian sebelumnya. ${ }^{10}$ Subjek dengan lama kerja tertinggi 7 tahun dan terendah $<1$ tahun.

\section{Tabel 1 Jumlah Kejadian Kecemasan pada Sif Pagi dan Malam}

\begin{tabular}{ccc}
\hline Kejadian & Sif Pagi & Sif Malam \\
\cline { 2 - 3 } Cemas & $\mathbf{n = 2 3}$ & $\mathbf{n = 2 3}$ \\
\hline Normal & 8 & 9 \\
Cemas & 15 & 14 \\
\hline
\end{tabular}

Tabel 1 menunjukkan bahwa subjek yang mengalami cemas lebih banyak dibanding dengan subjek yang normal ketika menyelesaikan sif pagi maupun sif malam. Hal tersebut dapat disebabkan oleh perbedaan beban kerja yang dialami satpam Universitas Islam Bandung (Unisba) antara sif pagi dan sif malam. 
Tabel 2 Asosiasi Sif Kerja dan Kategori DASS 42

\begin{tabular}{|c|c|c|c|c|c|c|}
\hline \multirow{2}{*}{ Sif } & \multicolumn{3}{|c|}{ Kategori DASS } & \multirow{2}{*}{ PR } & \multirow{2}{*}{ IK 95\% } & \multirow{2}{*}{$\mathbf{p}$} \\
\hline & Normal & Cemas & Total & & & \\
\hline Pagi & 8 & 15 & 23 & 0,93 & $0,59-1,45$ & 0,76 \\
\hline Malam & 9 & 14 & 23 & & & \\
\hline
\end{tabular}

Analisis yang dilakukan adalah kekuatan asosiasi prevalensi ratio (PR) dan Uji McNemar's Chi-Square didapatkan nilai PR 0,93 (IK 95\%=0,59-1,45) yang menunjukkan tidak terdapat perbedaan prevalensi cemas antara sif pagi dan sif malam. Kedua kategori tersebut sama-sama memiliki prevalensi cemas sebagai prevalensi terbanyak. Keadaan tersebut dikonfirmasi dengan uji hipotesis, yaitu $\mathrm{p}=0,76$ yang lebih besar daripada signifikansi yang ditentukan, yaitu alfa 0,05 . Hal tersebut berarti tidak terdapat perbedaan proporsi yang signifikan secara statistik antara sif kerja dan kecemasan pada satpam Universitas Islam Bandung.

\section{Pembahasan}

Hasil penelitian satpam Universitas Islam Bandung menunjukkan bahwa sif kerja pagi dan malam dengan durasi kerja masing-masing dua belas jam selama dua hari sama-sama memiliki jumlah kejadian cemas yang lebih besar dibanding dengan yang tidak cemas. Hasil penelitian ini berbeda dengan penelitian yang dilakukan oleh Yani dkk.7 Perbedaan tersebut dapat disebabkan oleh beban kerja yang berbeda karena penelitian tersebut dilakukan pada pegawai pabrik mesin penggilingan tebu. Belum pernah ada penelitian sebelumnya pada satpam terkait dengan sif kerja dan kecemasan. Banyak faktor yang dapat memengaruhi kecemasan pada satpam ketika melakukan sif kerja seperti kebiasaan merokok, masalah rumah tangga, genetik, dan juga lingkungan. ${ }^{11}$ Faktor kecemasan yang berasal dari pekerjaan selain sif kerja adalah durasi kerja.

Durasi kerja yang lama ketika menjalani sif, yakni selama dua belas jam dapat menjadi penyebab kecemasan. Durasi kerja yang baik adalah delapan jam setiap sif kerja dengan tiga sif kerja (pagi, sore, malam). ${ }^{5}$ Jumlah jam kerja yang dijalani oleh satpam Universitas Islam Bandung dalam satu minggu adalah enam puluh jam. Penelitian di Inggris menunjukkan bahwa jumlah jam kerja lebih dari 55 jam dalam satu minggu memiliki angka risiko kecemasan dan depresi yang lebih tinggi bila dibanding dengan pekerja yang bekerja selama 41-55 jam dalam 1 minggu. Penelitian tersebut dilakukan pada pekerja yang telah bekerja selama 5 tahun. ${ }^{10}$ Penelitian Hordaland Health Studies juga menunjukkan bahwa pria yang bekerja dengan durasi 49-100 jam dalam satu minggu memiliki kejadian kecemasan yang lebih tinggi. ${ }^{12}$ Durasi kerja satpam Universitas Islam Bandung termasuk dalam kategori lebih dari 55 jam dan 49-100 jam dalam satu minggu. Hal ini sesuai dengan kedua penelitian sebelumnya.

Beban kerja tersebut terbagi menjadi beban kerja kuantitatif dan kualitatif. ${ }^{13}$ Faktor lain yang dapat memengaruhi kecemasan pada para pekerja adalah beban kerja kuantitatif. ${ }^{14}$ Perbedaan beban kerja secara kuantitatif antara satpam dan pekerja pabrik dapat menjadi alasan perbedaan jumlah kejadian kecemasan pada sif malam. Pekerja pabrik memiliki tuntutan beban kerja kuantitatif yang sama baik pada saat sif pagi ataupun sif malam sehingga gangguan irama sirkadian pada sif malam automatis mengakibatkan beban kerja kuantitatif yang lebih besar pada pekerja pabrik apabila bekerja di malam hari. ${ }^{15}$ Pekerja pabrik memiliki jumlah kejadian kecemasan yang lebih besar pada sif malam dibanding dengan sif pagi. ${ }^{7}$

Satpam di Universitas Islam Bandung mempunyai beban kerja kuantitatif yang cenderung lebih banyak pada sif pagi bila dibanding dengan saat sif malam berdasar atas hasil wawancara dan observasi. Pada sif pagi, satpam Universitas Islam Bandung diharuskan melakukan tugas untuk menyambut tamu atau dosen, mengaturtempatparkir, danmembantupenyeberangan bagi pejalan kaki di samping melakukan tugas menjaga keamanan. Interaksi dengan bermacam pihak juga lebih banyak dilakukan pada sif pagi. Sejalan dengan angka interpretasi DASS 42 yang menunjukkan dua responden mengalami tingkat kecemasan sangat berat di sif pagi, namun tidak ditemukan pada sif malam. Jumlah kecemasan secara keseluruhan juga lebih banyak pada sif pagi bila dibanding dengan sif malam selisih satu angka. Penyebab hal tersebut dapat berasal dari beban kerja pada malam hari yang dirasa lebih ringan karena satpam tidak perlu melakukan tugas lain selain menjaga keamanan di lingkungan kampus. Satpam Universitas Islam Bandung cenderung tidak banyak bergerak seperti yang dilakukan pada pagi hari. Walau demikian, gangguan irama sirkadian pada sif malam tetap dapat berpengaruh dalam menambah beban kerja di malam hari sehingga memengaruhi kecemasan. ${ }^{15}$ Perbedaan faktor beban kerja antara pekerja pabrik dan satpam yang telah disebutkan dapat menjadi penyebab perbedaan jumlah kecemasan antara dua profesi tersebut, walaupun sama-sama menjalani dua sif kerja.

\section{Simpulan}

Penelitian ini tidak mendapatkan hubungan antara sif kerja dan kejadian kecemasan pada satpam Universitas Islam Bandung (Unisba).

\section{Ucapan Terima Kasih}

Ucapan terima kasih kepada seluruh satpam bagian keamanan ketertiban Universitas Islam Bandung (Unisba.

\section{Daftar Pustaka}

1. Hyman S, Chisholm D, Kessler R, Patel V, Whiteford H. Mental disorders. Dalam: Jamison DT, Breman JG, Measham AR, Alleyne G, Claeson M, Evans DB, dkk., penyunting. Disease control priorities in developing countries. Edisi ke-2. New York: Oxford University Press; 2006. hlm. 60526.

2. National Association for Mental Health. Understanding anxiety and panic attacks. Mind [Internet]. 2015;6 [diunduh 31 Desember 
2017]. Tersedia dari: http://www.mind.org.uk/ media/1892482/mind_anxiety_panic_web.pdf.

3. Badan Penelitian dan Pengembangan Kesehatan. Riset Kesehatan Dasar (RISKESDAS) 2013. Jakarta: Departemen Kesehatan RI; 2013

4. Manuaba A. Ergonomi, kesehatan, dan keselamatan kerja. Dalam: Wignyosoebroto S, penyunting. Edisi ke-1. Surakarta: UNIBA Press; 2004. hlm. 371.

5. Nurmianto E. Ergonomi konsep dasar dan aplikasinya. Edisi ke-2. Surabaya: Guna Widya; 2008.

6. Øyane NMF, Pallesen S, Moen BE, Åkerstedt T, Bjorvatn B. Associations between night work and anxiety, depression, insomnia, sleepiness and fatigue in a sample of Norwegian nurses. PLoS One. 2013;8(8):1-7.

7. Yani F, Soleha TU, Larasati T, J M. Hubungan shift kerja malam dengan kejadian depresi, kecemasan dan stres pada pekerja di Bagian Maintenance Mesin Penggiling Tebu (Cane Roll Mill) PTPN VII Bunga Mayang. J Major [Internet]. 2014 Feb 14;3(6) [diunduh 18 Desember 2017]. Tersedia dari: http://juke.kedokteran.unila.ac.id/index. $\mathrm{php} / \mathrm{majority} /$ article/view/291/289.

8. Peraturan Kepala Kepolisian Republik Indonesia Nomor 24 Tahun 2007 tentang Sistem Manajemen
Pengamanan Organisasi, Perusahaan dan/atau Instansi/Lembaga Pemerintah.

9. Hardhana B, Budiono CS, Kurniasih N, Manullang EV, Susanti MI, Pangribowo S, dkk. data dan informasi profil kesehatan Indonesia 2016. Jakarta: Pusat Data dan Informasi Kementerian Kesehatan RI; 2017.

10. Virtanen M, Ferrie JE, Singh-manoux A, Shipley MJ, Stansfeld SA, Marmot MG, dkk. Long working hours and symptoms of anxiety and depression : a 5 -year follow-up of the Whitehall II study. NCBI. 2011 Dec;41(12):2485-94.

11. Ramaiah S. Kecemasan bagaimana mengatasinya penyebabnya. Jakarta: Pustaka Populer; 2005.

12. Kleppa E, Bjarte S, Grethe TS. Working overtime is associated with anxiety and depression. The Hordaland Health Study. JOEM. 2017 June;50(Issue 6):658-66.

13. Ivancevich JM, Konopaske R, Matteson MT. Perilaku dan manajemen organisasi. Edisi ke-7. Jakarta: Erlangga; 2006.

14. Nishitani N, Hisataka S, Akiyama I. Eating behavior related to obesity and job stress in male Japanese worker. Nutrition. 2009;25(1):45-50.

15. Coles ME, Schubert JR, Nota JA. Sleep, circadian rhythms, and anxious traits. Curr Psychiatry Rep. 2015;17(9):73. 